\title{
Dr Blalock's unfinished business
}

\author{
Ashish S. Shah, MD
}

\author{
From the Department of Cardiac Surgery, Vanderbilt University Medical Center, Nashville, Tenn. \\ Disclosures: Author has nothing to disclose with regard to commercial support. \\ Received for publication April 24, 2017; accepted for publication May 5, 2017; available ahead of print June 24, \\ 2017. \\ Address for reprints: Ashish S. Shah, MD, Department of Cardiac Surgery, Vanderbilt University Medical Center, \\ 5025 Medical Center East, 1215 21st Ave S, Nashville, TN 37232 (E-mail: ashish.s.shah@vanderbilt.edu). \\ J Thorac Cardiovasc Surg 2017;154:855 \\ $0022-5223 / \$ 36.00$ \\ Copyright (C) 2017 by The American Association for Thoracic Surgery \\ http://dx.doi.org/10.1016/j.jtcvs.2017.05.038
}

The study from Abadeer and colleagues reported in this issue of the Journal is an ambitious effort. ${ }^{1}$ The authors set out to better define the natural history of acute kidney injury in a high-risk cohort-patients in shock needing short-term mechanical support-using a retrospective registry. This cohort is a diverse group and includes heart transplant recipients, patients with acute coronary syndromes, and patients with postcardiotomy failure. Almost one-half of the study population was treated with extracorporeal membrane oxygenator (ECMO) support, and the remainder had a ventricular assist device. All treatments were at the discretion of the treatment teams and provided over a 5-year period. The authors elected to use a more nuanced classification system to grade kidney injury. Perhaps the most important finding of this study is the long-term renal recovery rate. The authors' ponclusions are predictable: severe kidney injury is bad, and some patients recover.

Our understanding of kidney injury continues to evolve. It is becoming increasingly clear that subtle preoperative renal insufficiency, anemia, perioperative venous congestion, arterial blood pressure, and timing of renal replacement are critical regulators of short-term renal function. It also is reasonable to presume that these factors play roles in long- term renal function. Given that maintaining cardiac output might not be the sole necessary condition for renal protection, these variables also likely reflect the quality of support. Unfortunately, however, this current study is not equipped to tackle these issues. Moreover, the diverse patient population and support platforms pose a challenge to interpreting long-term consequences. For example, would the postcardiotomy patients have done better with ECMO and higher blood pressure compared with patients supported with a centrally placed short-term continuous-flow device? And then there is the large group (more than one-half) of patients who died. Death cheats us of many things, and here it clouds the long-term consequences of support quality. We simply us to complete.

\section{References} 154:856-64.e4 Press; 1966.

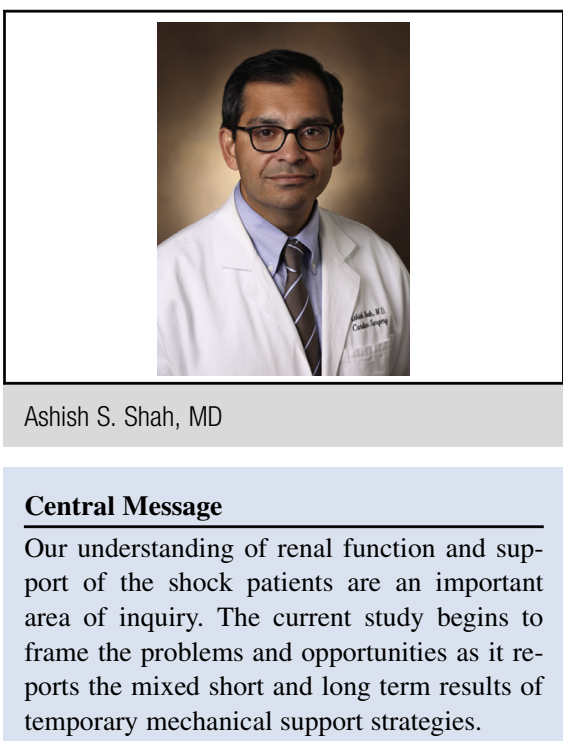

See Article page 856 .

will never know what would have happened to the renal function of a patient who died because of bleeding or terminal brain injury.

The authors are to be congratulated for taking a more nuanced view of renal injury in a complex and messy dataset. Future studies will need to bring better tools to explore and answer these questions. The most important mandate is prospectively collecting biomarkers of renal injury and variables associated with support quality. Abadeer and coworkers have certainly called attention to this problem, which should stimulate renewed interest in the age old problem of shock. Dr Blalock is assuredly smiling somewhere. His extensive studies in shock are worth a reread. What is noticeably absent during his Vanderbilt period is an examination of renal function in experimental shock. His unfinished business remains for

1. Abadeer AI, Kurlansky P, Chiuzan C, Truby L, Radhakrishnan J, Garan R, et al. Importance of stratifying acute kidney injury in cardiogenic shock resuscitated with mechanical circulatory support therapy. J Thorac Cardiovasc Surg. 2017;

2. Ravitch M. The Papers of Alfred Blalock, Volume 1. Baltimore: Johns Hopkins 